Check for updates

London, UK

Cite this as: BMJ 2021;373:n1636 http://dx.doi.org/10.1136/bmj.n1636 Published: 25 June 2021

\title{
NHS Test and Trace: lack of progress is "deeply disappointing”
}

\section{Ingrid Torjesen}

Serious problems remain with the overall speed, reach, and levels of public compliance of the NHS Test and Trace service, a damning report from the National Audit Office (NAO) has found.

A clear integrated national and local testing and tracing strategy is needed by July, when England is to come out of lockdown. But it is currently unclear whether free mass asymptomatic testing using lateral flow devices will continue, says the report. ${ }^{1}$

Plans for improving the overall test and trace process, including tackling how best to support citizens to come forward for tests and comply with self-isolation requirements, should be set out by October, it adds, when NHS Test and Trace is to be subsumed into the new National Institute for Health Protection, which will bring further risks and challenges.

Meg Hillier MP, chair of the House of Commons Public Accounts Committee, said the report showed that the service was "still plagued by the same problems" as at the beginning of the year and described the lack of progress as "deeply disappointing."

"As we learn to live with covid, NHS Test and Trace must urgently improve performance to deliver the effective system we so badly need," she said.

A mass rollout of asymptomatic testing began in autumn 2020 which saw NHS Test and Trace distribute 691 million lateral flow devices in England between October 2020 and 26 May 2021, but only 96 million (14\%) of these have been registered as used because there is no system in place to monitor or ensure that everyone reports their results, the report says.

NHS Test and Trace has reduced the time taken between a person booking an in-person polymerase chain reaction (PCR) test and their contacts being asked to self-isolate, but this represented a minority of tests, the report says.

The service does not have targets for how quickly the contacts of those testing positive should be reached for other types of PCR tests, such as home-based tests, and its targets do not cover the period between a person experiencing symptoms and coming forward for a test.

While NHS Test and Trace's turnaround of in-person PCR tests taken in the community has improved, with 90\% of results received within 24 hours in April 2021 compared with $38 \%$ in October $2020,{ }^{2}$ performance dropped to $17 \%$ during December 2020 when infections surged.

The overall effectiveness of the test and trace process relies on public compliance, which is "still low or variable," the report says. Only a minority of people who develop symptoms request a test, and not everyone self-isolates in line with requirements, but
NHS Test and Trace has no targets for increasing the number of people coming forward for a test or self-isolating.

Local authorities' involvement in tracing activities has increased significantly, the NAO says, but while data sharing has improved, local authorities still cannot access all the data they need to deal with localised outbreaks.

NHS Test and Trace spent €13.5bn (€15.7bn; \$18.8bn) of its £22.2bn budget in 2020-21, of this £10.4bn went on testing, £1.8bn on identifying and containing local outbreaks, and €o.gbn on tracing.

Some testing and tracing services are still being procured under emergency regulations, without competition. The proportion awarded using emergency regulations fell from $46 \%$ in April-June 2020 to $6 \%$ in January-March 2021, but in terms of contract value the amount awarded in this way more than doubled, from £1.1bn to £2.6bn. It also continues to rely heavily on consultants, with $45 \%$ of staff at its central office being consultants as of mid-April 2021.

More flexibility has been introduced into contact centre contracts but NHS Test and Trace is still paying for large amounts of underused capacity. It aims for a 50\% average utilisation rate for contact tracers but daily utilisation rates have remained "well below" this since November 2020, falling to around $11 \%$ in February 2021.

Gareth Davies, the head of the NAO, said, "Since we last reported in December, NHS Test and Trace has introduced a lot of changes, including mass testing, closer working with local authorities, and initiatives to identify and contain variant forms of covid-19. However, some pressing challenges need to be tackled if it is to achieve its objectives and deliver value for taxpayers, including understanding how many lateral flow devices are actually being used and increasing public compliance with testing and self-isolation.”

Justin Madders MP, Labour's shadow health minister, called the report "damning." He added, "The government has been told time and again that if we are going to bring down cases, it needs to ensure people can afford to self-isolate, but it has refused to listen.

"If lateral flow tests are going to play their part in helping society reopen, ministers need to make sure results are registered-it's astounding that 550000 tests have gone missing."

National Audit Office. Test and trace in England: progress update. June 2021. www.nao.org.uk.

Wise J. Covid-19: Test and trace system must improve its below par performance, NAO concludes. BMJ2020;371:m4796.

doi: 10.1136/bmj.m4796 pmid: 33310777 